\title{
Reflexive ordering of percent free PSA in patients: Do we need to ask the question?
}

\author{
Jean-Baptiste Lattouf, MD, FRCSC
}

See related article on page 317.

T he authors have studied the practice of "reflexive" ordering of percent free prostate-specific antigen (PSA) in patients that have a total PSA value between 4 and 10 ng. ${ }^{1}$ This ordering is standard procedure at their tertiary care centre and possibly across other centres. They conclude that nearly half of the percent free PSA measurements are probably not warranted and result in $\$ 8647.76$ of unnecessary yearly costs at their institution.

This figure may be small when one considers the global budget of a tertiary care centre, but it should be kept in mind that only one test is being analyzed here. One wonders what the cumulative cost would be if other "reflexive" laboratory tests across specialties are factored in. ${ }^{2,3}$ Further, due to the nature of the data analysis, the number of unnecessary tests is probably underestimated. Indeed, the study does not take into account the unfortunate, but common, scenarios where PSA is ordered for clinical conditions known to result in false positive values, such as in the setting of cystitis or after catheter placement. These tests would be considered screening tests since the subjects may not have a diagnosis of cancer, and therefore the tests may have been falsely deemed justified.

Asking whether a reflexive laboratory measurement is warranted in a condition as controversial and heterogeneous as prostate cancer (whether for screening or follow-up) is akin to asking whether taking a history and performing a physical are necessary to treat a patient. It is unfortunate that the authors had to ask this question, but I congratulate them for critically assessing this routine practice, and concluding what should be considered obvious by many clinicians.

Département de Chirurgie-Urologie, Centre Hospitalier de l'Université de Montréal, Montréal, QC

Competing interests: None declared.

This paper has been peer-reviewed.

\section{References}

1. Allard C, Yip P, Blasutig I, et al. Does the reflexive measurement of free PSA have a role in a tertiary cancer centre? Can Urol Assoc J 2010;4:317-20.

2. Collier CP, Clark AF, Bain J, et al. Functional testosterone: biochemical assessment of hypogonadism in men-report from a multidisciplinary workshop hosted by the Ontario Society of Clinical Chemists. Aging Male 2007;10:211-6.

3. Rowe LR, Aldeen W, Bentz JS. Prevalence and typing of HPV DNA by hybrid capture II in women with ASCUS, ASC-H, LSIL, and AGC on ThinPrep Pap tests. Diagn Cytopathol 2004;30:426-32.

Correspondence: Dr. Jean-Baptiste Lattouf, Professeur adjoint de clinique, Département de ChirurgieUrologie, Centre Hospitalier de I'Université de Montréal, 1058 Rue St-Denis, Montréal, QC H2X 3J4; fax: 514-412-7411; jean-baptiste.lattou@umontreal.ca 